\title{
Manipulative damage to the endothelium of infant and adult donor corneas
}

\author{
Israel N Nartey, Emil S Sherrard, Arthur D McG Steele
}

\begin{abstract}
Six human donor corneas were studied with the scanning electron microscope to quantify the hazards to the endothelium during the excision of corneoscleral buttons. Although the number studied was small, it was found that: (1) striae were more numerous in the flaccid, very young, donor corneas (under 1 year old) than in the more rigid adult corneas: (2) iridocorneal endothelial touch can result in loss of the posterior membrane and death of the touched endothelial cells. This corroborates the findings of other investigators. Both findings are important, because these conditions reduce the quality of the donor cornea for transplantation.
\end{abstract}

The success of penetrating keratoplasty depends to a large extent on the donor corneal endothelium. This may be influenced by a number of factors including donor age, cause of death, technical handling, time from death to enucleation, and method and duration of storage..$^{1-6}$

Modern preservation procedures involve the use of donor corneoscleral buttons. The extra handling for their excision puts the endothelium at risk of damage in addition to that due to post-mortem changes such as folding. Roozitalab and colleagues ${ }^{5}$ have shown that excessive traction on the cornea during excision can result in the formation of stretch striae and that these represent damage to the endothelium. They have established an excision technique which is currently recommended by the American Eye Bank Association. Grutzmacher et $a l^{8}$ have compared the above recommended excision technique with another in which several donor eyes were incised in the sclera $1 \mathrm{~mm}$ from the limbus with the loss of the anterior chamber (AC). Their findings paralleled those of Roozitalab et al..$^{5}$ In addition they noted that striae were more frequent in young donors and in in-situ (globe retained in orbit) excisions. They suggested that this may be due to firmer attachments between the longitudinal ciliary muscles and the spur in the young, who incidentally represented the larger proportion of in-situ excisions.

Recently the protective effect of $1 \%$ sodium hyaluronate against endothelial cell damage from various types of trauma including stretching and rubbing of the cornea against other anterior ocular structures (iris, lens, anterior vitreous) was investigated in cats by Bahn et al. ${ }^{9}$ They demonstrated small round areas of endothelial cell damage in corneas that were rubbed across the iris-lens surface. In contrast a cornea that was stretched by grasping Descemet's membrane showed large linear patterns of damage.
More recently Saggau et $a l^{10}$ compared chondroitin sulphate corneal storage medium (CSM) and $\mathrm{K}$-sol with regard to structural preservation of the endothelium by scanning electron microscopy (SEM). They found no consistent difference in the efficacy of corneal preservation between the two media. However, they observed large areas of endothelial cell disruption in the periphery of most of the corneas and speculated that this damage may be due to touch of the corneal endothelium by the iris.

Personal experience is that the young eye is in general more difficult to handle than the adult eye, that the cornea is more flaccid and prone to distortion and stria formation, and that the $\mathrm{AC}$ is relatively easy to lose, with consequent iridocorneal endothelial touch (ICET). It was felt that these factors also contribute to endothelial damage, and, since an increasing number of surgeons now employ infant donor corneas, ${ }^{112}$ this study aimed to investigate their significance.

\section{Materials and methods}

Six human donor eyes, one pair aged 8 months, one pair aged 62 years, one eye aged 3 months, and one aged 16 years (Table I) were used for this study. The ocular history was normal for all the donors. Each eye was examined with the slitlamp and the wide field specular microscope (the Pocklington, Keeler/Konan), particularly for the presence of striae and folds, before storage in a moist chamber at $4^{\circ} \mathrm{C}$ for $1-58 \mathrm{~h}$. One eye $(6$ in Table I) was initially so stored for one and a half hours, then the cornea was excised and kept in McCarey-Kaufman (M-K) medium at $4^{\circ} \mathrm{C}$ for $120 \mathrm{~h}$. The presence and intensity of posterior corneal rings (PCRs) $)^{1314}$ in the whole eyes were used as an indication of corneal rigidity. With sterile technique a corneoscleral button was prepared from each eye by making a scleral incision 2-3 $\mathrm{mm}$ posterior to the limbus into the suprachoroidal space with a no. 15 Bard-Parker blade. The incision was completed with curved corneal scissors and the ciliary body attachments to the scleral spur were separated. Care was taken to maintain the AC. ${ }^{7}$ Because the eyes of the very young donors $(1,2,3$ in Table I) were too small to fit into currently available commercial eye stands, they were wrapped in gauze and hand held during corneal excision. Some difficulty was encountered in these cases during separation of the ciliary body from the scleral spur.

Under a dissecting microscope $0.1 \mathrm{ml}$ of $2 \%$ glutaraldehyde solution was added to the aqueous humour by injection into the $\mathrm{AC}$ via the initial incision in eye 4. Care was taken not to touch the endothelium. The incision was com-
Correspondence to: $\mathrm{Dr} I N$ Nartey, Moorfields Eye Hospital, City Road, London

Accepted for publication 9 January 1990

\footnotetext{
brane showed large linear patterns of damage.
} 
TABLE I Donor information

\begin{tabular}{|c|c|c|c|c|c|c|c|}
\hline Eye & $\begin{array}{l}\text { Age } \\
(y r)\end{array}$ & Sex & $C O D$ & $\begin{array}{l}\text { Death to } \\
\text { enucleation }\end{array}$ & $\begin{array}{l}\text { Enucleation to } \\
S L \text { exam. }{ }^{\star}\end{array}$ & $\begin{array}{l}\text { Time in } M C \\
\text { at } 4^{\circ} \mathrm{C}\end{array}$ & $\begin{array}{l}\text { Time in } M K \\
\text { at } 4^{\circ} \mathrm{C}\end{array}$ \\
\hline $\begin{array}{l}1 \\
2 \\
3 \\
4 \\
5 \\
6\end{array}$ & $\begin{array}{l}8 / 12 \\
8 / 12 \\
3 / 12 \\
62 \\
62 \\
16\end{array}$ & $\begin{array}{l}M \\
M \\
F \\
M \\
M \\
M\end{array}$ & $\begin{array}{l}\text { Cot death } \\
\text { Cot death } \\
\text { Cot death } \\
\mathbf{R} \text { arrest } \dagger \\
\text { R arrest } \dagger \\
\text { Suicide }\end{array}$ & $\begin{array}{l}7 \cdot 75 \mathrm{~h} \\
8 \mathrm{~h} \\
4 \cdot 16 \mathrm{~h} \\
25 \mathrm{~min} \\
30 \mathrm{~min} \\
11 \mathrm{~h}\end{array}$ & $\begin{array}{l}3 \mathrm{~h} \\
3 \cdot 25 \mathrm{~h} \\
2 \mathrm{hr} \\
2 \cdot 5 \mathrm{~h} \\
3 \mathrm{~h} \\
1.5 \mathrm{~h}\end{array}$ & $\begin{array}{l}21 \mathrm{~h} \\
21.25 \mathrm{~h} \\
1.5 \mathrm{~h} \\
58 \mathrm{~h} \\
58.25 \mathrm{~h} \\
1.5 \mathrm{~h}\end{array}$ & $\begin{array}{l}- \\
- \\
- \\
\overline{1} \\
120 \mathrm{~h}\end{array}$ \\
\hline
\end{tabular}

^Enucleation to slit-lamp examination. $M C=$ moist chamber. $M K=M c C a r e y-K a u f m a n$ medium $\mathrm{COD}=$ cause of death. $\nmid$ Respiratory arrest.

pleted with corneal scissors. The corneoscleral button (4 in Table I) was then placed without distortion into more glutaraldehyde solution and left for $2 \mathrm{~h} .0 \cdot 1 \mathrm{ml}$ of aqueous humour was aspirated from the fellow eye ( 5 in Table $I$ ) in order to allow the corneal endothelium to touch the iris, and possibly the lens. After 1 minute the AC was reformed with $0 \cdot 1 \mathrm{ml}$ of $2 \%$ glutaraldehyde solution, and the cornea was excised and fixed as for eye 4 . The fixed rigid button was easy to handle. The corneoscleral button of eye 6 was excised in the normal way ${ }^{75}$ without prior fixation and was relatively difficult to handle. It was then fixed in glutaraldehyde for $2 \mathrm{~h}$. All six corneoscleral buttons were prepared for scanning electron microscopy (SEM) as described elsewhere $^{16}$ and examined in a Hitachi S520 scanning electron microscope at $20 \mathrm{kV}$.

\section{Results}

CLINICAL OBSERVATIONS

Slit-lamp examination of the corneas of the six human donor eyes at the prestorage post-mortem times shown in Table I revealed minimal to moderate stromal oedema. Folds were obvious in

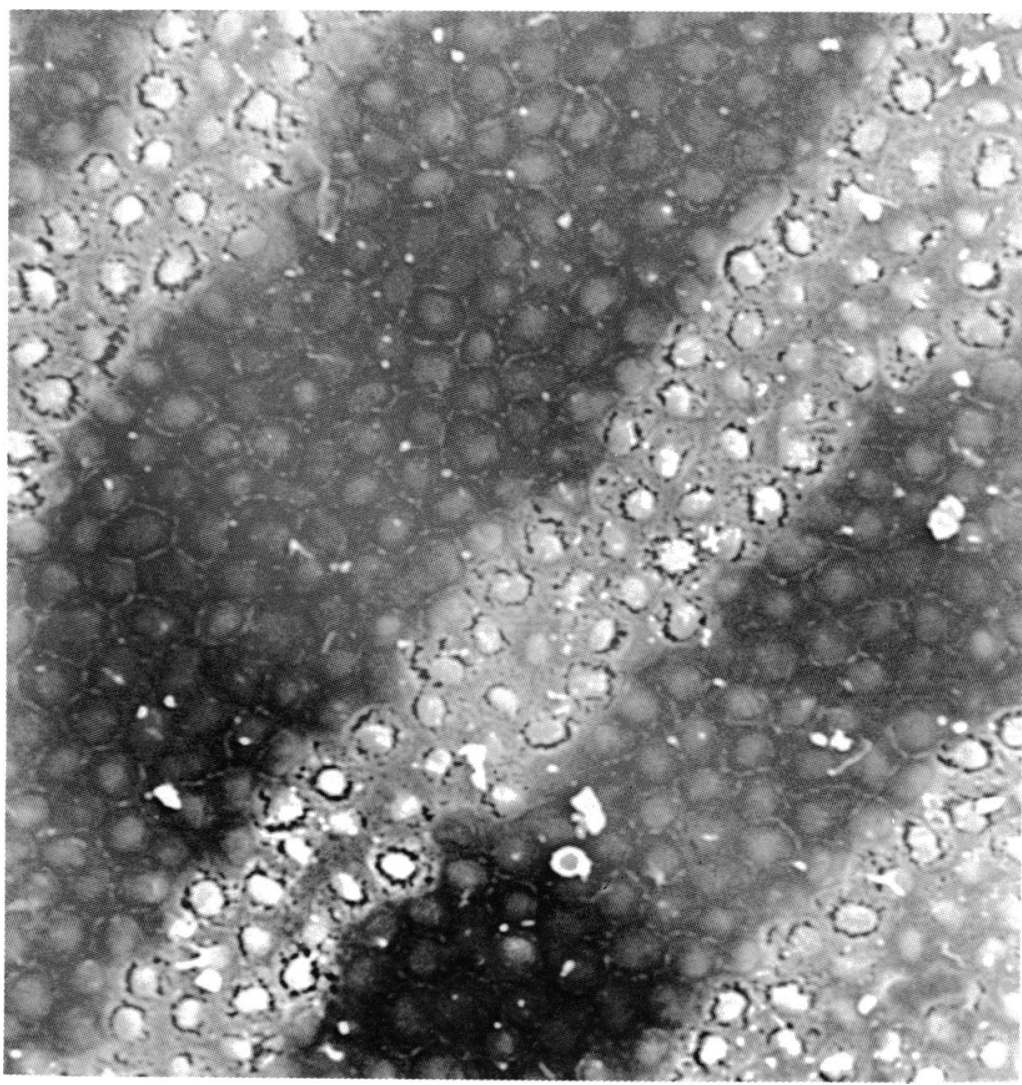

Figure 2: Higher magnification SEM of the same specimen showing striae consist of degenerate endothelial cells with disrupted posterior cell membranes. $(\times 420$.)

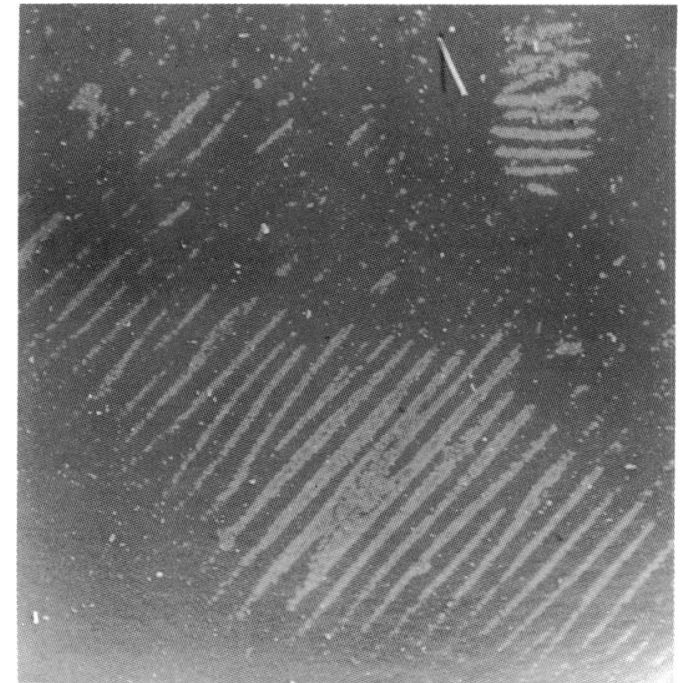

Figure 1: Low power SEM of corneal endothelial striae in specimen $1 .(\times 18$.

the older corneas $(4,5,6$ in Table I) but none was seen in the very young. Subsequent slit-lamp examination at intervals during moist chamber storage showed a progressive increase in the haze of oedema in all the eyes and in the number of folds in the adults. Folding did not occur in the very young corneas.

A fairly adequate specular microscopical view was achieved in all whole eyes. The very young eyes $(1,2,3$ in Table $I)$ showed a regular mosaic of small, rounded, similar cells with occasional 'dark areas' of about the same size as an endothelial cell. These possibly represented intracellular vacuoles or dead cells. ${ }^{17}$ In specimens 4, 5 , and 6 much of the endothelium was obscured by folds and oedema. Nevertheless, large areas of normal, polymegethous endothelium were seen. Posterior corneal rings, induced by applanation with the objective of the specular microscope, were distinct in the older corneas, unclear in specimen 6 , and absent in the very young corneas. This indicates rigidity of the old and flaccidity of the young cornea. ${ }^{1314}$

\section{OBSERVATIONS DURING EXCISION}

Corneoscleral disc removal from the adult eyes was relatively easy because both hands were free to carry out the procedure, and the ciliary body was easy to separate from the scleral spur. It was more difficult in the very young because only one hand was free to effect the excision. This resulted in stretch and distortion of the corneas in eyes 1 and, to a less extent, 2, with partial loss of AC in 3 (Table I). Striae were obvious after excision in all the very young smooth corneas but were indistinguishable from folds in the adult corneas.

\section{SEM}

Low magnification SEM revealed numerous greyish white parallel lines (Fig. 1) in the very young corneas (1, 2 and 3 in Table I). These were assumed to represent the striae induced during excision of the corneoscleral buttons. Higher magnification revealed that the lines consisted of rows of endothelial cells, 3-6 cells wide, whose nuclei were exposed by the loss of the posterior 


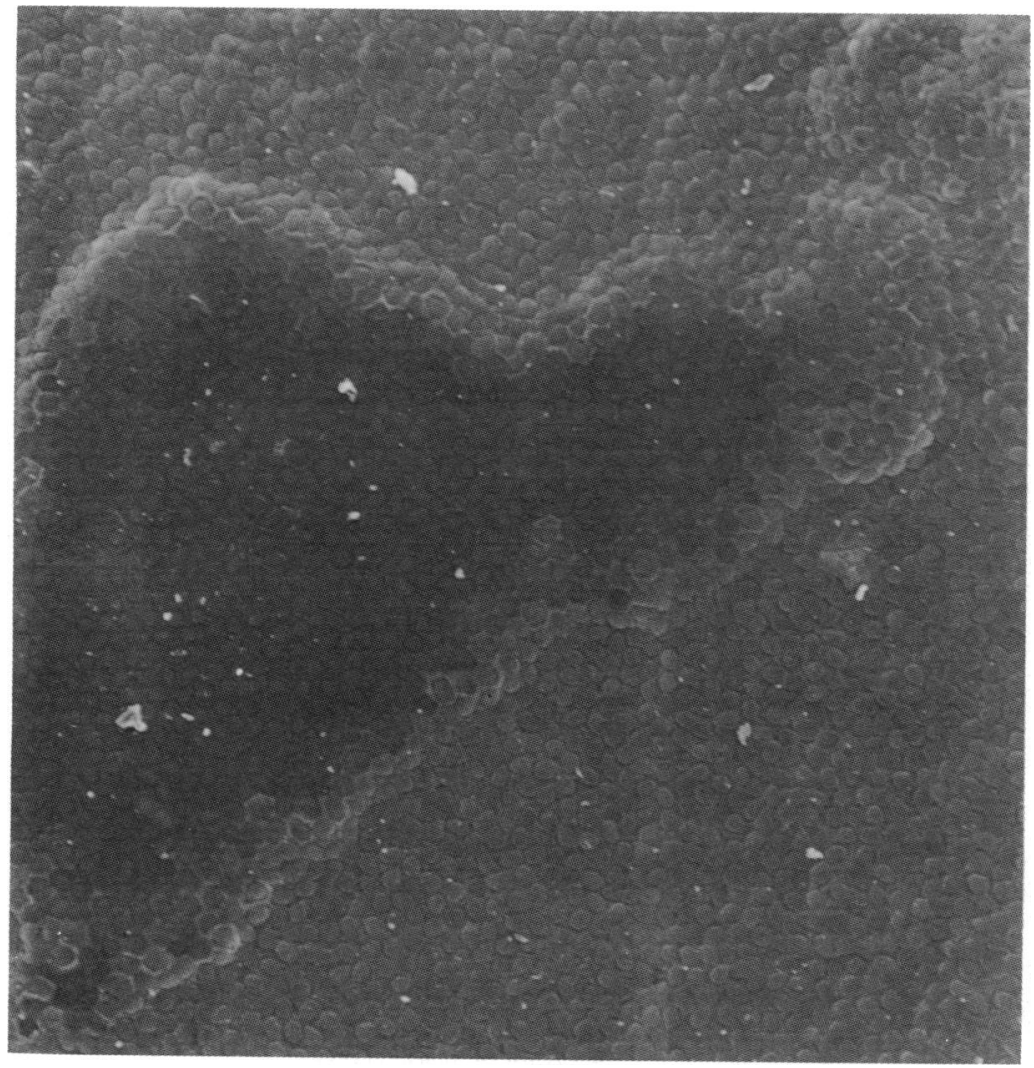

Figure 3: Low power SEM of localised area of endothelium touched by iris in specimen 3. $(\times 185$.

cell membranes (Fig 2). Damage of this kind was more extensive in specimen 1 than in 2 - the fellow cornea - presumably because excision of the former was more difficult. The intervening endothelium appeared normal. In specimen 3 (Table I) low power SEM revealed dark patches with raised borders in the endothelium in addition to striae (Fig 3).

Higher magnification showed that in these patches the cells were altered as illustrated in

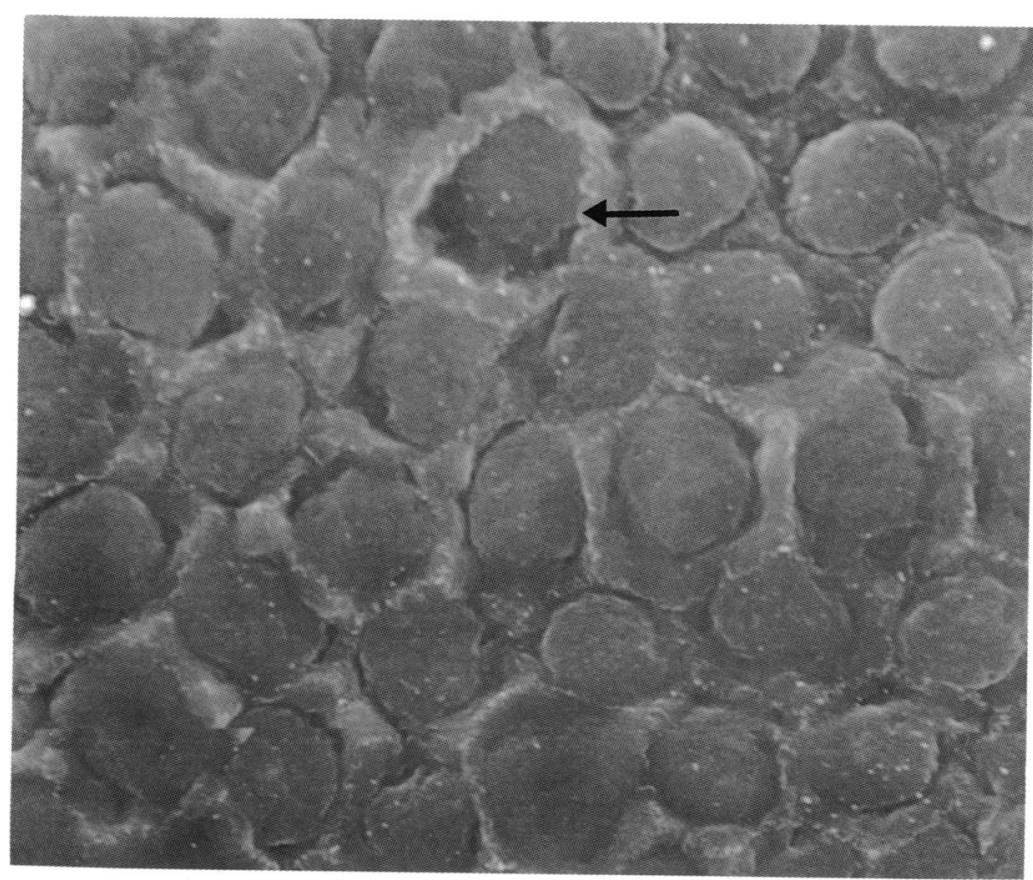

Figure 4: Higher magnification SEM of localised area of endothelium touched by iris shown in Figure 3. Endothelial cells are present but a cell appears to have lost its posterior cell membrane
(arrow). $(\times 1200$.
Figure 4. Since the AC was partially lost in this specimen, it seems probable that the changes resulted from ICET.

In specimen 4 (Table I) endothelial cell damage was mostly confined to folds, though there were a few peripheral striae. In the fellow cornea, specimen 5 (Table I) in which ICET was permitted, patches of similarly damaged cells were present in addition to those on the folds and of the striae. Although the 16-year-old cornea 6 (Table I) showed minimal traction damage, cell destruction was severe along the folds. It is noteworthy that in the adult corneas $4,5,6$ in Table I the few striae crisscrossed with the folds. This confirmed that folds and striae are different entities, as previously noted. ${ }^{16}$

\section{Discussion}

Damage to the donor corneal endothelium in the form of striae, best seen by retroillumination, has been reported by several investigators, ${ }^{57818}$ who have made suggestions as to their cause, significance, and prevention. However, there have been no discussions of their occurrence in the very young donor corneas which are becoming used more frequently. ${ }^{11}{ }^{12}$ Currently available commercial eye stands have been designed primarily to accommodate the eye of the adult donor. However, they can be modified to fit eyes of young donors - for example, by inverting the eye support of the Micra eye stand ${ }^{15}$ over its distance piece. Alternatively, the young donor eye may be wrapped in gauze and hand held during the excision of the cornea. This increases the risk of damage to the corneal endothelium, which is already high owing to easy stretchability and distortion of the flaccid cornea, with loss of the AC and ICET.

Endothelial changes due to stretch have been demonstrated clinically ${ }^{19} 20$ and experimentally. ${ }^{89}$ In vivo, however, the changes are reversible and therefore of little consequence. Changes of similar appearance are induced by stretching in donor eyes. Here, in the in-vitro state they persist and so affect the quality of the graft material. The factors that cause striae, such as folding and stretching, occur at the time of enucleation and/or excision of the corneoscleral button, but the striae themselves may not become visible until much later.

In their comparison of excision techniques Grutzmacher $e t a l^{8}$ found that the number of striae correlated with the degree of stretch applied to the cornea, and that they were more numerous in young donors. This they considered was because many of them were excised in situ (globe retained in orbit). These authors did not state whether infant donors were included in their series; and the four cases reported by Roozitalab et $a l^{5}$ were of adult donors. It seemed reasonable to assume, however, that the great flaccidity of the young cornea allows greater distortion and therefore stria formation. Indeed, in the present study the very young donors showed more traction damage especially, in 1 (Table I, Fig 2), and to a less extent in 2 and 3 (Table I) than in the adults; and all excisions were ex situ. Since we had only three infant corneas to study, it is difficult to draw 


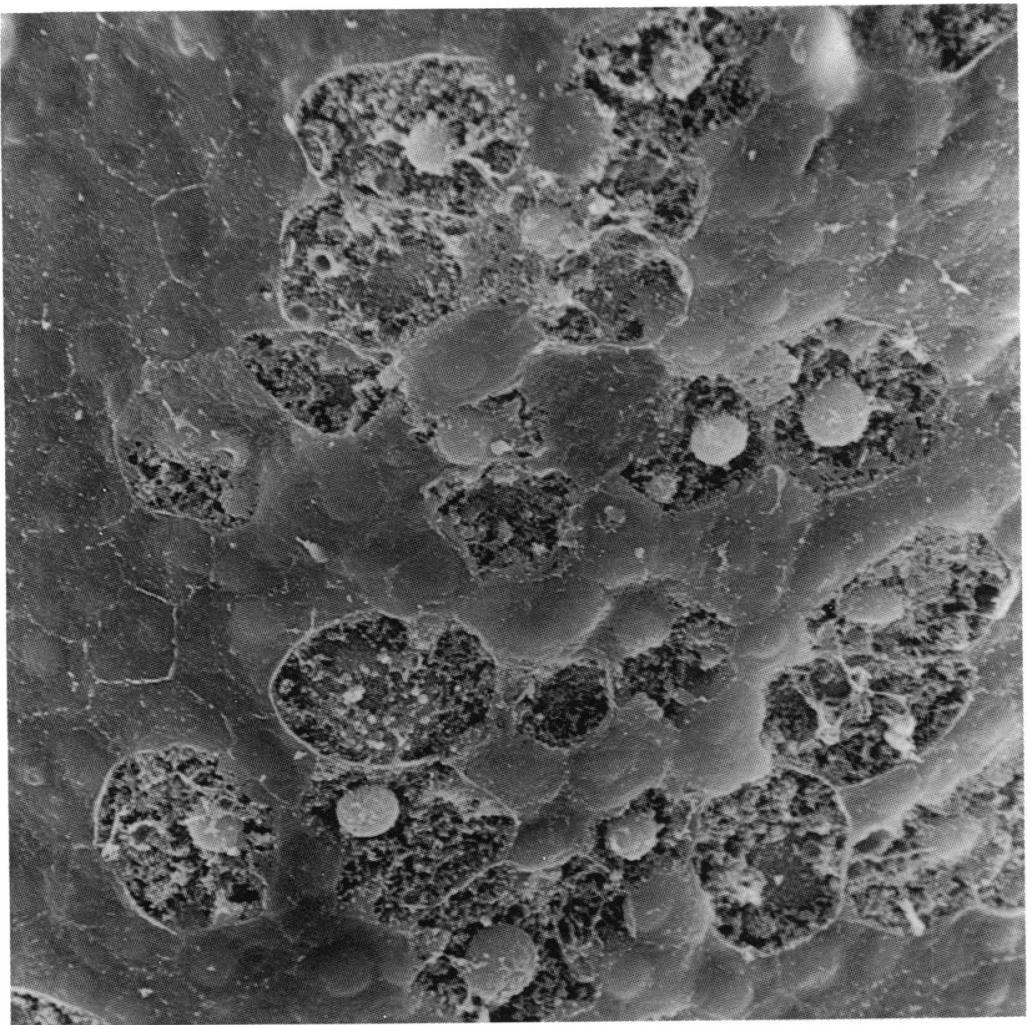

Figure 5: SEM of adult donor cornea showing endothelial cells damaged by iris touch. $(\times 725$.

valid conclusions as to whether or not infant corneas are more susceptible to stria formation because of their flaccidity than the more rigid adult cornea.

Polack $^{21}$ showed that contact between the human endothelium and iriș caused damage to the former. In the present study damage as seen by SEM similar to that found by Polack was noted in specimen 5 in which the $A C$ was partially lost (Fig 5). Undoubtedly this resulted from ICET as in Polack's case, and confirms our suspicion and that of Saggau et al. ${ }^{10}$

Although our numbers are small, this and other studies ${ }^{59}$ show that excessive traction of the cornea and ICET can result in damage to a significant number of endothelial cells which is irreversible in the in-vitro, donor, state.

This damage reduces the quality of the donor cornea and should be avoided.

It is proposed that donor material, especially the very young, be used fresh when possible to eliminate one excision procedure. If the cornea must be stored, extreme care should be taken during excision to avoid $\mathrm{AC}$ loss and excessive traction. From the observations of $\mathrm{McCrae}$ et $\mathrm{al}^{22}$ and Bahn et $a l^{9}$ it would appear that the use of a viscoelastic substance such as methylcellulose to prevent contact between the endothelium and iris would be useful. Furthermore, it is clearly desirable that stored corneoscleral buttons be examined immediately before their use for penetrating keratoplasty in order to eliminate those with excessive striae.

If the use of infant donor corneas for transplantation is to be encouraged, it would be desirable to have the appropriate instruments for their handling. Developing an eye holder suitable for infant donors would be a major first step to reducing the number of striae and overcoming the difficulties encountered during the excision of corneoscleral buttons. This is now under investigation.

The authors wish to thank Miss E Bennett for typing the manuscript, Dr W Ng for expert technical assistance, and the Department of Medical Illustration for the photographic processing.

1 Hoefle FB. Human corneal donor material: in vivo studies. Arch Ophthalmol 1969; 82: 361-7.

2 Kaufman HE, Robbins JE, Capella JA. The human corneal endothelium. Am f Ophthalmol 1966; 61: 835-41.

Stocker FW. The transparency of corneal grafts. In: Rycroft PV, ed. Corneo-plastic surgery (Proc 2nd Int Corneo-Plastic P, ed. Cor ort: Pergamon Press, 1967: 495-9.

4 McKinon JR, Walters GD. Cadaver storage time: an important factor in donor cornea survival. Arch Ophthalmol important factor in

5 Roozital MH, Requard JJ, Fogle JA, Green WR, Graham CR Jr. Endothelial stretch striae in donor cornea: cause, significance and prevention. Maryland State Med F 1979; 28: $47-55$.

6 Schaeffer EM. Ultrastructural changes in moist chamber corneas. Invest Ophthalmol Vis Sci 1963; 2: 272-82.

$7 \mathrm{Krachmer} \mathrm{JH}$ Jr. Medical standards of the Eye Bank Association of America. Section 8: 1. 1984

8 Grutzmacher RD, Oiland D, McKillop BR, Bunt-Milam AH. Donor corneal endothelial striae. Am f Ophthalmol 1986; 102: 508-15.

9 Bahn CF, Grosserode R, Musch DC, et al. Effect of $1 \%$ sodium hyaluronidase (Healon) on a non-regenerating (feline) corneal endothelium. Invest Ophthalmol Vis Sci 1986; 27: corneal end

10 Saggau DD, Bourne WM. A comparison of two preservation media (CSM) and K-sol by scanning electron microscopy of media (CSM) and K-sol by scanning electron microscopy of preserved $429-32$.

11 Pfister RR, Breaud S. Aphakic refractive penetrating keratoplasty using newborn donor corneas. A preliminary report on an alternative approach to refractive correction. Ophthalmology 1983; 90: 1207-12.

12 Fong LP, Gladstone D, Casey TA. Corneoscleral rim cultures: donor contamination. A case of fungal endophthalmitis transmitted by K-sol cornea. Eye 1988; 2 : 670-6.

13 Sherrard ES, Buckley RJ. Endothelial wrinkling: a complication of clinical specular microscopy. In: Trevor-Roper P, ed. The cornea in health and disease. Trans VI Congress Euro Soc The cornea in health and disease. Trans VI Congress Euro Soc Ophthalmol. London: Academic Pre

14 Sherrard ES, Novakovic P, Speedwell L. Age-related changes of the corneal endothelium and stroma as seen in vivo by specular microscopy. Eye 1987; 1: 197-203.

15 Steele ADMcG, Pierse D. Mastering the donor eye: a new device for obtaining donor corneal discs. Br $\mathcal{F}$ Ophthalmol 1978; 62: 86-8

16 Nartey IN, Ng W, Sherrard ES, Steele ADMcG. Posterior corneal folds and endothelial cell damage in human donor eyes. BrF Ophthalmol 1989; 73: 121-5.

17 Sherrard ES. Characterisation of changes observed in the corneal endothelium with the specular microscope. Invest Ophthalmol Vis Sci 1978; 17: 322-6.

18 Alfonso E, Tucker GS, Batlle JF, Mandelbaum S, Gellende $\mathrm{H}$, Foster RK. Snailtracks of the corneal endothelium. Ophthalmology 1986; 93: 344-9.

19 Norn . Vital staining of corneal endothelium in cataract extraction. Acta Ophthalmol (Kbh) 1971; 49: 725-33.

20 Miller D, Weiss JN. The effect of corneal stretch on the endothelium. Ophthalmic Surg 1981; 12: 731 .

21 Polack FM. Penetrating keratoplasty. In: Polack FM, ed Corneal transplantation. New York: Grune and Stratton, 1977: 135-46.

22 McCrae S, Edelhauser HF, Hyndiunk RA, Burd E, Schultze RO. Effects of sodium hyaluronidase, chondroitin sulfate and methylcellulose on the corneal endothelium and intraocular pressure. Am f Ophthalmol 1983; 95: 332-41. 